\title{
Genome-wide screening for genes whose deletions confer sensitivity to mutagenic purine base analogs in yeast Elena I Stepchenkova ${ }^{1}$, Stanislav G Kozmin ${ }^{1,2}$, Vladimir V Alenin ${ }^{1}$ and Youri I Pavlov*1,3
} \begin{abstract}
Omaha, NE 68198, USA
Email: Elena I Stepchenkova - stepchenkova@yahoo.com; Stanislav G Kozmin - kozmin@niehs.nih.gov; Vladimir V Alenin - alenin@alenin.usr.pu.ru; Youri I Pavlov* - ypavlov@unmc.edu

* Corresponding author
\end{abstract}

Address: ${ }^{1}$ Department of Genetics, Sankt-Petersburg State University, Sankt-Petersburg, 199034, Russia, ${ }^{2}$ Laboratory of Molecular Genetics, National Institute of Environmental Health Sciences, RTP, NC 27709, USA and ${ }^{3}$ Eppley Institute for Research in Cancer and Allied Diseases, the Department of Biochemistry and Molecular Biology, and the Department of Pathology and Microbiology, University of Nebraska Medical Center,

Published: 02 June 2005

BMC Genetics 2005, 6:31 doi:10.1|86/|47|-2156-6-31
Received: 26 January 2005

Accepted: 02 June 2005

This article is available from: http://www.biomedcentral.com/|47|-2/56/6/3I

(c) 2005 Stepchenkov et al; licensee BioMed Central Ltd.

This is an Open Access article distributed under the terms of the Creative Commons Attribution License (http://creativecommons.org/licenses/by/2.0), which permits unrestricted use, distribution, and reproduction in any medium, provided the original work is properly cited.

\begin{abstract}
Background: N-hydroxylated base analogs, such as 6-hydroxylaminopurine (HAP) and 2-amino6-hydroxylaminopurine (AHA), are strong mutagens in various organisms due to their ambiguous base-pairing properties. The systems protecting cells from HAP and related noncanonical purines in Escherichia coli include specialized deoxyribonucleoside triphosphatase RdgB, DNA repair endonuclease $\mathrm{V}$, and a molybdenum cofactor-dependent system. Fewer HAP-detoxification systems have been identified in yeast Saccharomyces cerevisiae and other eukaryotes. Cellular systems protecting from AHA are unknown. In the present study, we performed a genome-wide search for genes whose deletions confer sensitivity to HAP and AHA in yeast.
\end{abstract}

Results: We screened the library of yeast deletion mutants for sensitivity to the toxic and mutagenic action of HAP and AHA. We identified novel genes involved in the genetic control of base analogs sensitivity, including genes controlling purine metabolism, cytoskeleton organization, and amino acid metabolism.

Conclusion: We developed a method for screening the yeast deletion library for sensitivity to the mutagenic and toxic action of base analogs and identified 16 novel genes controlling pathways of protection from HAP. Three of them also protect from AHA.

\section{Background}

The accurate replication and repair of genetic material, which is a prerequisite for normal functioning of the eukaryotic genome and the prevention of cancer, relies on coordinated and faithful DNA synthesis. One important mechanism that ensures a high fidelity of DNA replication is a "cleansing" of the DNA precursor pool from deoxyribonucleoside triphosphates containing a modified base
[1-4]. Such modified bases may have ambiguous basepairing properties that will result in a high mutagenic activity after their incorporation into DNA during replication. A classic example of the detoxification mechanism is the elimination of dUTP and 8-oxo-dGTP from the dNTP pool by the E. coli dUTPase and MutT proteins, respectively $[1,5]$. 
<smiles>[H]/N=C\N=C/N=CNC=N</smiles><smiles>ONc1ncnc2[nH]cnc12</smiles>

6-Hydroxylaminopurine
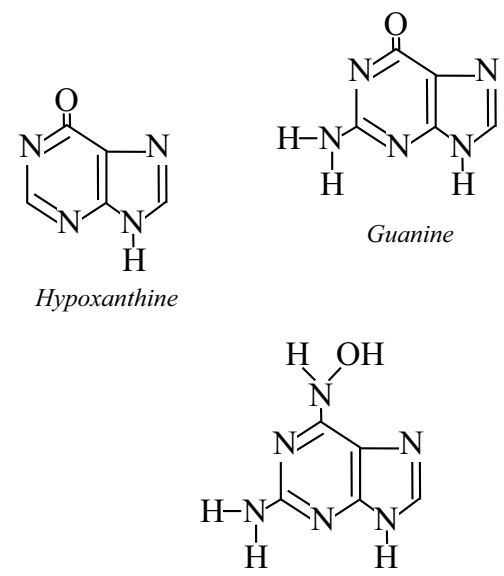

2-Amino-6-Hydroxylaminopurine

\section{Figure I}

Chemical structures of HAP and AHA and natural purine bases.

Purine analogs 6-hydroxyaminopurine (HAP) and 2amino-HAP (AHA) are powerful mutagens in bacteria, yeast, and higher eukaryotes [6,7]. It has been suggested that HAP-deoxyriboside-triphosphate (dHAPTP) is a possible endogenous contaminant of nucleotide pools under peroxyl radical stress [8]. HAP and AHA closely resemble the natural purines, hypoxanthine and xanthine (Fig. 1), and therefore, could be exploited to investigate the mechanism preventing mutations that are caused by noncanonical purine nucleotides [9-11].

It was proposed that purine salvage enzymes convert base analogs to the corresponding deoxyribonucleoside triphosphates, which are misincorporated or misreplicated during DNA synthesis, resulting in induction of mutations $[12,13]$. HAP-induced mutagenesis in yeast is elevated in strains with defects in proofreading activity of replicative DNA polymerases $[14,15]$ and does not depend on excision, mutagenic recombination, and mismatch repair systems [14-16]. We have described several systems protecting cells from the mutagenic and inhibitory effects of HAP (see review [16]). One is the novel molybdenum cofactor-dependent system in E. coli [17]. It has yet to be determined if a similar system exists in higher eukaryotes. Another, versatile HAP-detoxification pathway relies upon the action of triphosphatase, Ham1p, which hydrolyze HAP-containing ribo- and deoxyribo-nucleotides to nucleoside monophosphates, and which prevent incorporation of base analog into DNA and RNA. We initially described the elevated sensi- tivity to HAP in yeast due to mutations in the HAM1 gene [18]. When we cloned and sequenced the HAM1 gene, we found that it has homologs in many organisms, from bacteria to humans [13], and proposed that the gene might code for new triphosphatase [16]. Then, the crystal structure of the Ham 1p homologue from a thermostable bacterium (protein Mj0226) was determined [19]. It was found that the Ham $1 p$ ternary structure has common features with MutT. Homologs of the yeast Ham1p from other organisms possessed triphosphatase activity on dITP, ITP, XTP, and dHAPTP substrates (Kozmin and Pavlov, unpublished; Burgis and Cunnigham, personal communication; and [19-21]).

There are additional, less thoroughly studied, factors modulating purine base analogues mutagenesis in yeast (see [16] for review). For example, aah1 mutants are sensitive to HAP, suggesting that adenine deaminase Aah1p may deaminate HAP base to hypoxanthine [16].

In the present study, we carried out a genome-wide search for HAP and AHA sensitive mutants. The release of several complete sets of deletion mutants by the Yeast Deletion Project provides a powerful approach for different types of genome screens in yeast [22]. Haploid and diploid strains have already been used to detect new genes controlling sensitivity to different agents such as UV, ionising radiation, iron, and methyl methane sulfonate (MMS) [23-27], as well as spontaneous mutability [28]. This approach, when combined with other genomics approaches, helps to establish the biological functions of uncharacterized ORFs in yeast, many of which have human orthologs. This approach also allows us to decipher the network responses to endogenous and environmental stress [29]. The present study is the first systematic, genome-wide search for the mutations conferring sensitivity to mutagenic purine base analogs.

\section{Results}

\section{Development of the screening method}

To develop a useful method for searching the yeast mutants sensitive to base analogs, we calibrated the experimental conditions using the wild-type strain, BY4742, and two previously described HAP-sensitive mutants, ham1 and aah1 (see $[6,16]$ ), created on BY4742 background. As shown in Fig. 2 and described in Materials and Methods, yeast were grown in a 96-well microtiter plate and then transferred, using a multiprong replicator device, to YPD plates containing base analogs. An induction of the Can ${ }^{\mathrm{r}}$ mutants was monitored by replica-plating to the minimal-medium plates containing L-canavanine.

The results are presented in Fig. 3. The left panel of Fig. 3 shows the induction of canavanine-resistant mutants by HAP and AHA; and the right panel represents the survival 


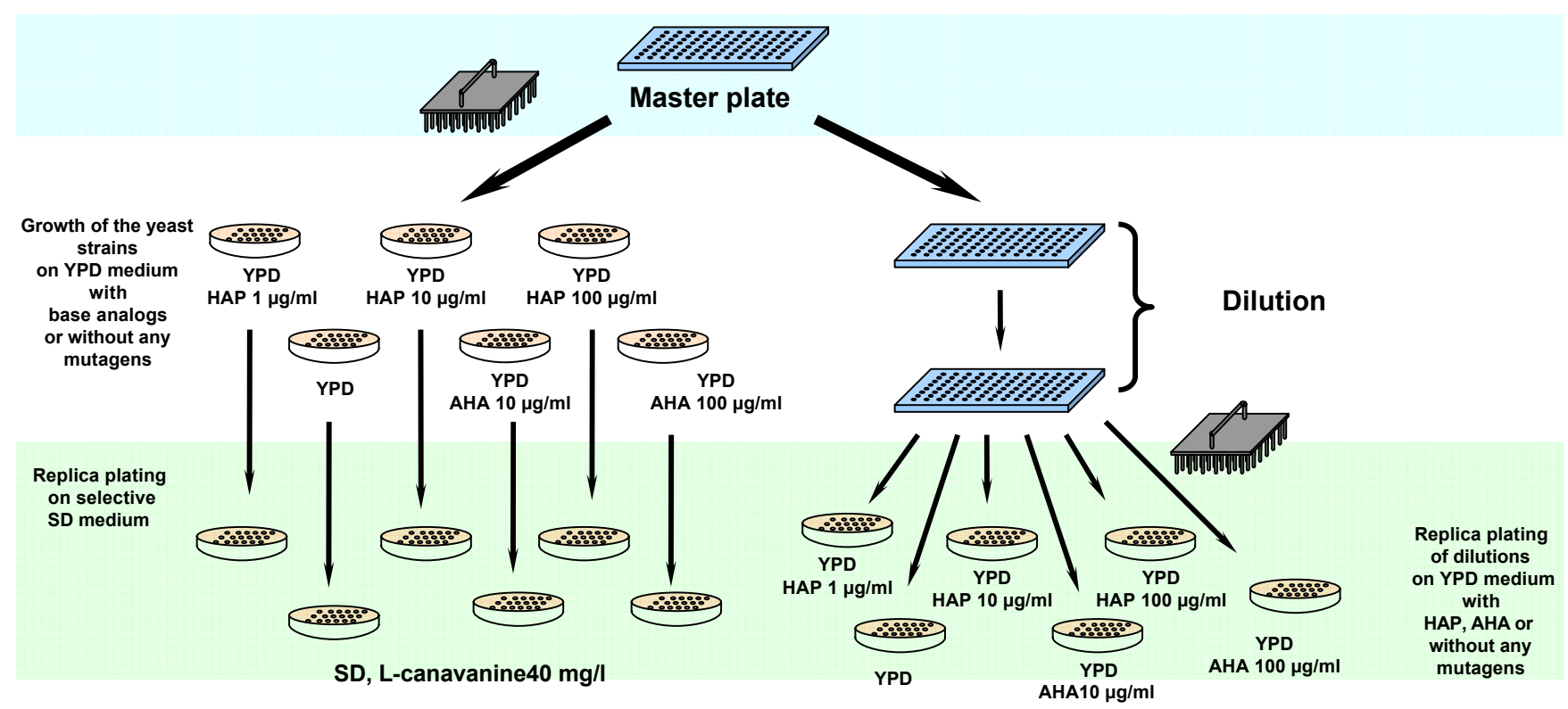

\section{Test for the induction of Can' mutants by the base analogs HAP and AHAP}

\section{Survival test}

Figure 2

Scheme of the protocol for screening the yeast deletions library for base analog sensitivity and induced mutagenesis.

of the tested strains on YPD plates in the presence of base analogs. In the wild-type strain, as in the ham 1 and aah1 mutants, 1-3 spontaneous canavanine-resistant colonies per spot arise in the absence of mutagen (Fig. 3A and 3B, left panel). In our experimental conditions, $1 \mu \mathrm{g} / \mathrm{ml}$ of HAP did not induce $\operatorname{Can}^{r}$ mutants in the wild-type strain. A moderate induction of $\mathrm{Can}^{\mathrm{r}}$ clones (fewer than ten per spot) was observed at $10 \mu \mathrm{g} / \mathrm{ml}$ of HAP and a very strong HAP-induced mutagenesis was observed in the wild-type strain at $100 \mu \mathrm{g} / \mathrm{ml}$ of HAP (Fig. 3A, left panel). For comparison, $100 \mu \mathrm{g} / \mathrm{ml}$ of AHA were only moderately mutagenic (compare Fig. $3 \mathrm{~A}$ and Fig. 3E, left panel). Furthermore, both HAP and AHA did not affect the viability of the wild-type strain, even at the maximal concentration of $100 \mu \mathrm{g} / \mathrm{ml}$ (Fig. 3A and 3E, right panel).

In the ham 1 strain, $1 \mu \mathrm{g} / \mathrm{ml}$ of HAP induced Can ${ }^{\mathrm{r}}$ mutants with the similar frequency that was observed in the wildtype strain at 2 orders in magnitude higher concentration of analog, $100 \mu \mathrm{g} / \mathrm{ml}$ (compare Fig. 3A and 3B, left panel, phenotype of hypermutability, HM). The hypersensitivity of the ham 1 mutant to the toxic action of HAP was clearly detectable at $100 \mu \mathrm{g} / \mathrm{ml}$ of HAP (Fig. 3B, right panel). We will refer later to this phenotype as hypersensitivity, HS. Note that a reduction of the number of canavanine-resist- ant clones at 10 and $100 \mu \mathrm{g} / \mathrm{ml}$ of HAP, in comparison with $1 \mu \mathrm{g} / \mathrm{ml}$ of HAP observed in the ham 1 mutant (Fig. $3 \mathrm{~B}$, left panel, another manifestation of hypersensitivity phenotype, HS), is also due to a dramatic decrease of survival. When the aah1 mutant was tested (Fig. 3B, second row, for HAP and Fig. 3F, first row, for AHA), the drop of viability was less severe than that for the ham 1 mutant (phenotype of elevated sensitivity, S). HAP-induced mutagenesis was detectable at a low dose of $1 \mu \mathrm{g} / \mathrm{ml}$, but was much less compared to the ham 1 mutant (phenotype of elevated mutability, M). Mutagenesis was somewhat stronger at the dose $10 \mu \mathrm{g} / \mathrm{ml}$ and was not seen at $100 \mu \mathrm{g} /$ $\mathrm{ml}$ (another manifestation of elevated sensitivity, S). For the aah1 mutant, AHA-induced mutagenesis was moderate at the dose of $10 \mu \mathrm{g} / \mathrm{ml}$ and very strong at a concentration of $100 \mu \mathrm{g} / \mathrm{ml}$. The aah1 mutant exemplified what we expect to observe for mutants moderately sensitive to both HAP and AHA. These data suggested that the procedure we devised for micro-titre plate format is effective for the detection of mutants with altered parameters of HAP and AHA sensitivity and mutability.

\section{Screening of the deletion strains library}

We screened the yeast deletion strains library as described above. After an initial screening of 4,823 deletion strains, 
Induction of Can ${ }^{R}$ clones by HAP HAP0 HAP1 HAP10 HAP100

A.

$B$.
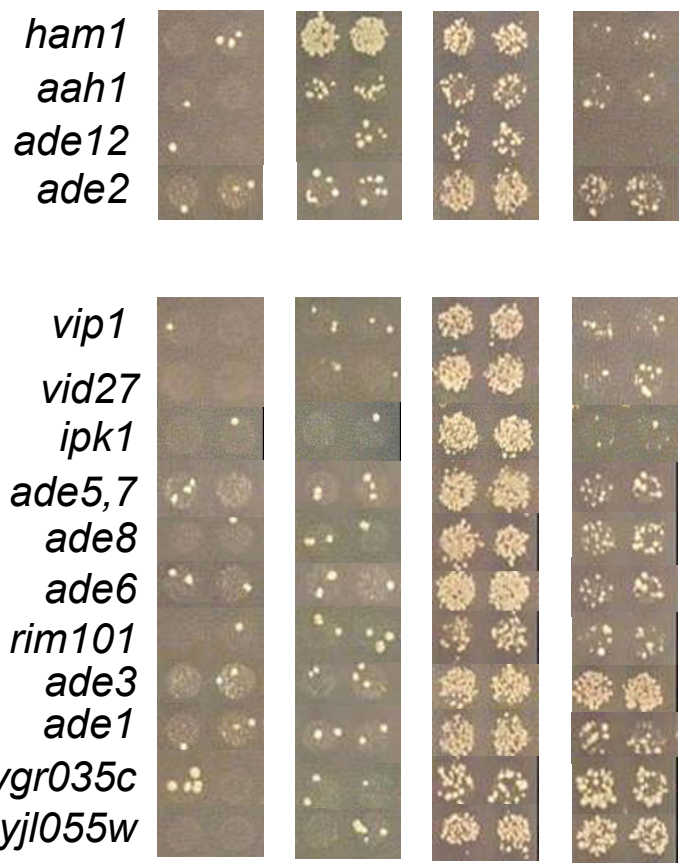

C.
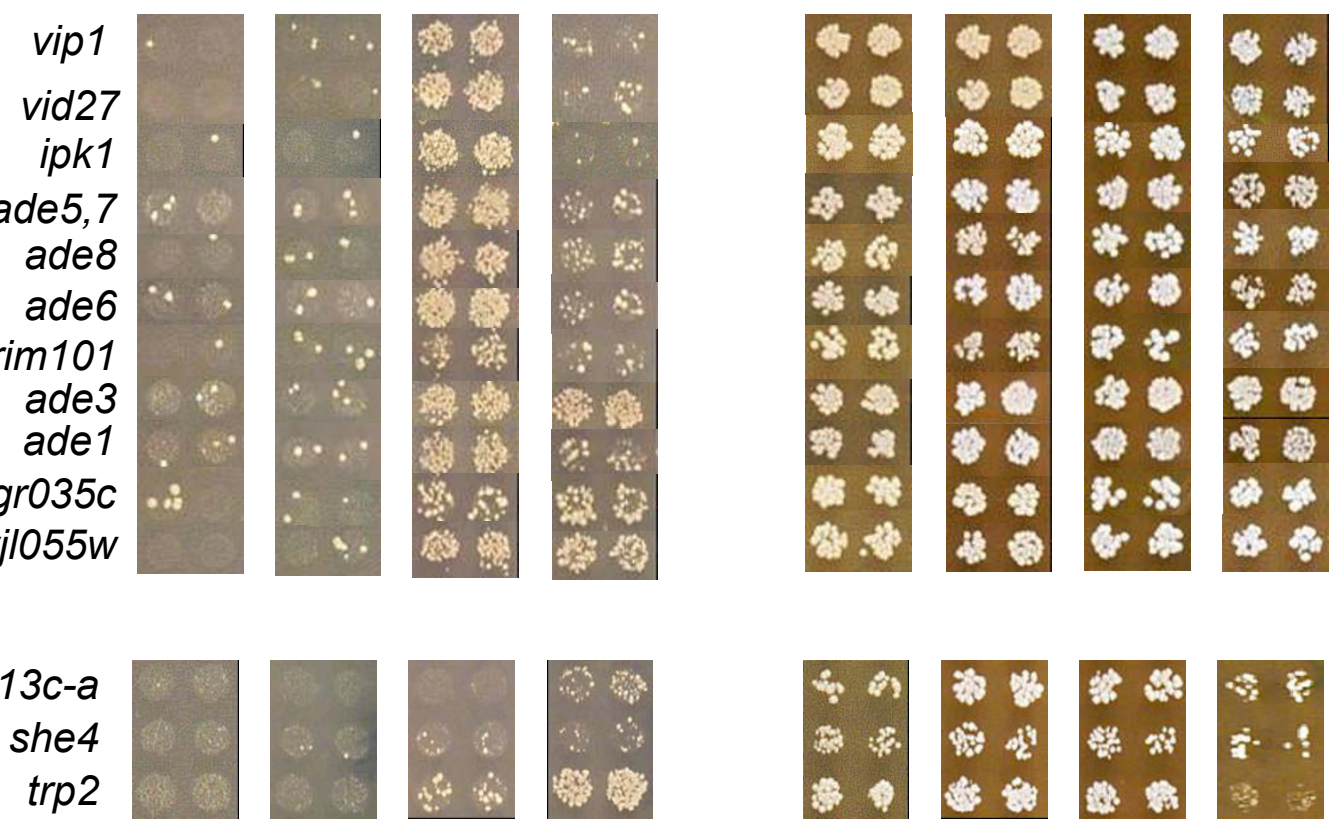

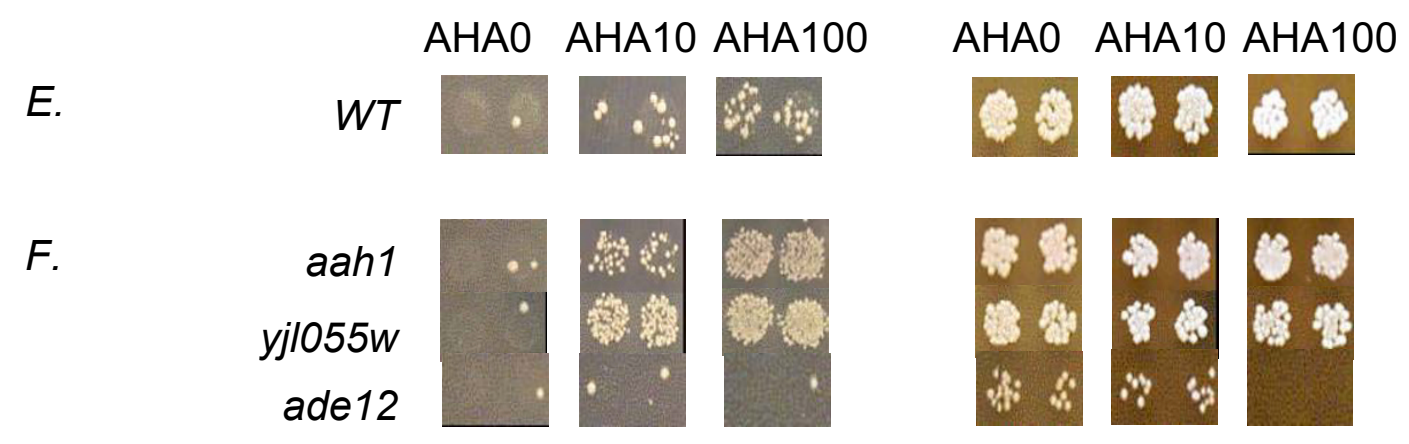

Figure 3

Results of the screening of the yeast deletion library for elevated mutagenesis and sensitivity in micro-titer plates. Left panel - Mutagenesis on selective plates with canavanine. Right panel - The estimation of the number of colonyforming units on YPD medium. 
Table I: HAP-sensitivity of the mutants selected in our screening.

\begin{tabular}{|c|c|c|c|c|c|}
\hline Class of mutants & $\begin{array}{c}\text { Gene or ORF name } \\
\text { deleted }\end{array}$ & Functional group & $\begin{array}{c}\text { Response HAP in spot } \\
\text { tests }{ }^{\dagger}\end{array}$ & $\begin{array}{c}\text { Induced mutant } \\
\text { frequency }\left(\times 10^{-7}\right) \text { by } \\
\operatorname{HAP}^{\#}\end{array}$ & $\begin{array}{c}\text { Survival in presence of } \\
\text { HAP\# }\end{array}$ \\
\hline Wild type & & & - & 400 & $100 \%$ \\
\hline \multirow{4}{*}{$\begin{array}{c}\text { Class I: mutants } \\
\text { hypersensitive to HAP }\end{array}$} & HAMI & DNA' & $\mathrm{HM}, \mathrm{HS}$ & 13000 & $17 \%$ \\
\hline & $A D E / 2 *$ & DNA & $\mathrm{HM}, \mathrm{HS}$ & 10000 & $30 \%$ \\
\hline & $A A H I *$ & DNA & $M, S$ & 5500 & $30 \%$ \\
\hline & $A D E 2$ & DNA & $M, S$ & 4400 & $70 \%$ \\
\hline \multirow{11}{*}{$\begin{array}{l}\text { II class: Mutants } \\
\text { sensitive to mutagenic } \\
\text { effect of HAP }\end{array}$} & VIPI & Cell ${ }^{2}$ & M, S & 840 & $76 \%$ \\
\hline & VID27 & Metabolic ${ }^{3}$ & M, S & $600^{\circ}$ & $82 \%$ \\
\hline & IPKI & Metabolic & M, S & 1400 & $100 \%$ \\
\hline & $A D E 5,7$ & DNA & $M$ & 1900 & $100 \%$ \\
\hline & ADE8 & DNA & $M$ & 1500 & $100 \%$ \\
\hline & ADE6 & DNA & $M$ & 1100 & $100 \%$ \\
\hline & RIMIOI & meiosis & $M$ & 1100 & $100 \%$ \\
\hline & $A D E 3$ & DNA & $M$ & 940 & $100 \%$ \\
\hline & $A D E I$ & DNA & $M$ & 860 & $100 \%$ \\
\hline & YGR035c & unknown & $M$ & $500^{\circ}$ & $100 \%$ \\
\hline & Yjl055w* & Metabolic & $M$ & $500^{\circ}$ & $100 \%$ \\
\hline \multirow{3}{*}{$\begin{array}{l}\text { Class III: Mutants } \\
\text { sensitive to killing }\end{array}$} & YMIOI3c-a & Unknown & S & $230^{\circ}$ & $60 \%$ \\
\hline & SHE4 & Cell & S & $600^{\circ}$ & $30 \%$ \\
\hline & TRP2 & Metabolic & HS & $250^{\circ}$ & $60 \%$ \\
\hline
\end{tabular}

t- HM - hypermutable, M - more mutable than wild-type, HS - hypersensitive, S - more sensitive than wild-type, see first paragraph od the Results Section for the explanation.

$\#-25 \mu \mathrm{g} / \mathrm{ml}$

I - 'DNA' - includes genes involved in the control of DNA precursor metabolism, purine salvage, DNA repair.

2 - 'Cell' - includes genes involved in cytoskeleton organization, cell walls and organelles.

3 - 'Metabolic' - includes genes involved in general metabolic pathways.

* - These mutants were also sensitive to the mutagenic or toxic effect of AHA (see Fig. 3).

${ }^{\circ}$ - small difference from the wild-type strain was reproducible and statistically significant by Wilcoxon-Mann-Whitney test.

43 mutants strains appeared to affect base analog-induced killing or mutagenesis. However, in subsequent testing of candidate strains in same type of plate tests, we have confirmed HAP-sensitivity of 16 mutants (Fig. 3, Table 1, column 4, where we refer to phenotypes of mutants according to abbreviations described in previous section). Next, we examined the mutability and survival of these 16 mutants in quantitative tests with HAP (see Materials and Methods). Based on the results of these two types of tests, we categorize HAP-sensitive strains in three groups, as shown in Table 1. Group I comprises, in addition to ham 1 and aah1 strains, mutants ade 12 and ade2. These strains were hypersensitive to the mutagenic and lethal action of HAP in both types of tests (Fig. 3 and Table 1, columns 46). Strains of this group were sensitive to the low doses (1 and/or $10 \mu \mathrm{g} / \mathrm{ml}$ ) of HAP, in contrast to the wild-type strain. The ade12 mutant was almost as mutable as the ham1 strain, but the hypermutability could only be demonstrated in a quantitative test, due to poor plating efficiency (compare Fig 3B, row 3 and Table 1, column 5, row 3 ). The ade2 mutant was as mutable as the aah1 mutant (Table 1). Deletion mutants of the first group showed variable degree of sensitivity to HAP-induced killing Table 1 , column 6).

Eleven mutants fall into Group II. Mutants of this class were sensitive to the mutagenic effect of HAP, but their growth was not severely inhibited on HAP-containing medium. As a result, there is a smaller difference, in comparison to mutants of the group I, or no difference in the 
number of Can ${ }^{\mathrm{r}}$ mutants induced by 10 and $100 \mu \mathrm{g} / \mathrm{ml}$ of HAP in spot-tests (Fig. 3C, Table 1, column 4). These strains produced some HAP-induced $\mathrm{Can}^{\mathrm{r}}$ mutants at 10 $\mu \mathrm{g} / \mathrm{ml}$ of HAP, whereas the parental strain was non-mutable at this HAP concentration. We also did not detect any substantial drops of viability after growth in liquid media containing $25 \mu \mathrm{g} / \mathrm{ml}$ of HAP (Table 1, column 6). Group II was not homogeneous in respect to HAP mutability and sensitivity. The six most sensitive mutants in the group are vip1, vid27, ade1, ade5,7, ade6, ade8, ipk1 and rim101 (see Table 1). These mutants showed a decrease in the number of $\mathrm{Can}^{\mathrm{r}}$ mutants in a qualitative test when concentration of HAP increased ten-fold (up to $100 \mu \mathrm{g} / \mathrm{ml}$ ), which is an indication of some cell death at very high doses of HAP (Fig. 3C). Mutants yjl055w, ygr035c, and ade3 were more resistant to HAP, since the number of $\mathrm{Can}^{\mathrm{r}}$ colonies was similar at 10 and $100 \mu \mathrm{g} / \mathrm{ml}$ of HAP. As could be seen from the results of quantitative assay, mutant classification is quite conditional and there is substantial variation in responses between mutants of the Group II, but all of them were more mutable that the wild-type strain.

Finally, Group III includes mutants she4, trp2, and yml013c- $a$; which were sensitive to HAP-induced killing, but not to HAP-induced mutagenesis (Fig. 3D and Table 1, column 6). In quantitative tests the yml013c-a and trp2 mutants were even less sensitive to the mutagenic action of HAP than the wild-type strain (Table 1). The she 2 mutant was slightly more mutable that the wild-type strain only in quantitative test. The existence of such a type of mutants suggests that the toxic effect of HAP in yeast may be not only due to the induction of lethal mutations, but also due to inhibition of certain metabolic pathways.

In the present study, we have also characterized three AHA-sensitive mutants, aah1, ade12, and yjl055w (Fig. 3E and 3F). Remarkably, all of these mutants were also sensitive to HAP (Fig. $3 \mathrm{C}$ and Table 1). Two of those mutants, aah1 and yjl055w, were AHA-hypermutable; whereas ade12 strain did not mutate in the presence of AHA, but was sensitive to AHA-induced killing. In a quantitative test, $50 \mu \mathrm{g} / \mathrm{ml}$ of AHA did not inhibit survival of the wildtype strain, aah1 and yjl055w strains; whereas survival of the ade 12 mutant was reduced to $50 \%$. In the aah1 and yjl055w strains, $50 \mu \mathrm{g} / \mathrm{ml}$ of AHA induced canavanineresistant mutants with the frequencies $120 \times 10^{-7}$ and 270 $\times 10^{-7}$, respectively, that was 4-9-folds higher than observed in the wild-type and ade12 strains $\left(30 \times 10^{-7}\right.$, in both strains).

\section{Discussion}

In this study, we elaborated the technology for testing base analog-induced mutability and killing of thousands of yeast strains in microtiter format (see Fig. 2). We found that the method is quite sensitive and reliable. Next, we screened the library of haploid yeast strains carrying deletions in all nonessential ORFs for the sensitivity to mutagenic base analogs HAP and AHA. We have found 16 novel HAP-sensitive mutants that fall into several groups, based on the sensitivity profiles (Fig. 3 and Table 1). One group comprises the mutants that are HAP-hypermutable and grow poorly in the presence of HAP. Another class comprises strains with elevated HAP-mutability that grow normally on medium containing HAP. Finally, the third group includes the mutants sensitive to HAP-induced killing, but not to HAP-induced mutagenesis. We have also isolated three AHA-sensitive mutants. All of them were HAP sensitive as well. We summarized the properties of the genes found in our screening in Additional file 1.

One interesting result from our study is that none of the genes involved in the control of base analogs sensitivity except two genes, YML013c-a and ade12, were found in screenings for genes controlling sensitivity to the other types of mutagens, MMS, UV, and ionizing radiation [2327] or for elevated spontaneous mutagenesis [28]. It was previously reported that deletion of the YML013c-a and ADE12 open reading frame specifically enhanced sensitivity to killing (as in case of HAP) induced by $\gamma$-radiation and bleomycin, but did not affect sensitivity to MMS, UV, and hydroxyurea $[23,30]$. It is known that there are overlaps of the sets of genes detected in genome screenings for the MMS-, UV- or ionizing radiation-sensitive strains [29]. Usually, those spectra include genes controlling DNA replication, recombination, and DNA repair. In our study, we did not find any of those genes. This is consistent with our earlier observation that the mutagenic action of HAP in $S$. cerevisiae does not depend on nucleotide excision repair, mutagenic repair, and mismatch repair [16]. A system to repair non-canonical purines and, probably HAP and AHA, in DNA has been recently characterized in E. coli $[9,10]$. It is possible that yeast $S$. cerevisiae lacks such a repair system.

Based on our data, we propose that, in yeast, the major base analogs protective mechanism is a control of the quality of DNA precursor pool that prevents incorporation of base analogs into DNA. This mechanism may work at several levels: transport of analogs into cells, detoxification of analogs by metabolic enzymes, maintenance of nucleotide pools, and fidelity control of DNA replication (Fig. 4). HAP and AHA are likely transported into the yeast cell by the same permeases, which are involved in transport of natural purines. One candidate is purine-cytosine permease, Fcy2p, a major purine (adenine, guanine, and hypoxanthine) and cytosine transporter in yeast [31]. According to our unpublished data, $f c y 2$ mutants are resistant to HAP. Thus, the active transport of HAP is the first critical step in the HAP mutagenic pathway. The next 
step is a conversion of the base analog to the corresponding ribonucleoside monophosphate by enzymes of the purine salvage pathway. Previously we observed that the inactivation of the APT1 gene, encoding adenine phosphoribosyl transferase, led to a severe decrease of the mutagenic effect of HAP [16], suggesting that this enzyme plays a key role in the biosynthesis of HAP-riboside-5'monophosphate (HAPMP). HAPMP then may be converted to the corresponding nucleoside triphosphate, which could be ambiguously incorporated into DNA by DNA polymerases and provoke replication errors in the subsequent replication cycles [13].

The mechanism preventing HAP- and AHA-induced toxicity most likely involves the conversion of base analogs to non-mutagenic metabolites by purine salvage enzymes. The main argument for this hypothesis is that HAP could be utilized by yeast cells as a sole purine source $[13,18,32]$. The first enzyme in this HAP and AHA detoxification pathway is adenine aminohydrolase, encoded by the AAH1 gene. Aah1p from several microorganisms has been biochemically characterized (see [33]). Is has a broad substrate specificity and is capable of converting both adenine and its six-substituted analogs into hypoxanthine in vitro. According to our data, yeast Aah1p may convert HAP to hypoxanthine [12] and AHA to guanine in vivo, since the inactivation of the AAH1 leads to a defect in this conversion that is readily detected by UV spectroscopy of yeast medium (unpublished observation). In the aah1 mutant, the base analog intracellular concentration increases. We propose that this causes the elevation of base analog-induced mutagenesis (Fig. 3B and 3E, Table $1)$.

Interestingly, in our screening we did not detect the amd1 mutant, deficient in AMP aminohydrolase, that catalyze deamination of AMP to IMP [34]. We disrupted this gene by the kanMX cassette in several yeast strains and did not see any effect on HAP-induced mutagenesis anywhere. Thus, deamination of HAP at the mononucleotide level does not play an important role in HAP detoxification. This can be due to several reasons: the inability of the Amd1p to hydrolyse HAPMP, the minor role of the AMD1 gene in yeast, or the short life-time of the HAPMP in yeast cells.

We have found that inactivation of adenilosuccinate synthase (ASS or Ade12p) encoded by the ADE12 gene strongly enhanced HAP-induced mutagenesis and AHAinduced killing (see Fig. 3B and 3F, and Table 1). The primary function of this enzyme is the conversion of IMP to SAMP in the pathway of AMP biosynthesis de novo (Fig. 4). We propose that the reason for this hypersensitivity is the dysregulation of purine biosynthesis, as follows. First, the blocking of this step of purine biosynthesis causes accu- mulation of IMP in the cell. The excess of IMP is probably toxic for the cell, since ade12 mutants have a slow-growth phenotype that can be rescued by blocks of the earlier steps of the de novo purine biosynthesis pathway (Dr. A. M. Zekhnov \{St-Petersburg State University\}, personal communication). Accumulated IMP can be phosphorylated to ITP by nucleotide phosporylases. Thus, we propose that, in the ade12 mutant, an excess of ITP may saturate Ham1p triphosphatase, an essential enzyme for the destruction of HAPTP and AHAPTP, which leads to increased HAP-sensitivity (see Fig. 3). The data obtained recently in bacteria are consistent with this hypothesis. It was shown that, in vitro, E. coli Ham 1p homologues protein, $\operatorname{RdgB}$, is a triphosphatase that acts to hydrolize noncanonical DNA precursors, dIPT and dXTP. The Ham1p protein was shown to possess a similar activity on dITP, dXTP, and dHAPTP substrates (Kozmin and Pavlov, unpublished; Burgis and Cunnigham, personal communication; and see refs. [19-21]). In E. coli, the $r d g B$ mutation is synthetically lethal with recA. As proposed, absence of RdgB leads to a dramatic increase of hypoxanthine and xanthine in DNA. Accordingly, base excision repair of such modified bases occurring in opposite strands may generate double strand breaks that require the RecA function to be repaired. However, over-expression of adenilosuccinate synthase PurA (homolog of yeast Ade12p) suppresses this lethality [9]. This suggests a critical role of ASS in the regulation of intracellular concentration of genotoxic hypoxanthine-containing nucleotides.

We found that certain mutations affecting IMP biosynthesis de novo enhance HAP-induced mutagenesis (Table 1). Seven of sixteen newly identified genes controlling HAP and AHA sensitivity are involved in AMP biosynthesis (see Additional file 1 and Fig. 3). It is known that the regulation of the AMP biosynthesis pathway by adenine is mediated by SAICAR, one of the precursors in adenine biosynthesis de novo [35]. The accumulation of certain purine biosynthesis by-products may play a role in the regulation of the nucleotide pool. A defect in endogenous purine biosynthesis probably alters nucleotide pools to favour dHAPTP mis-incorporation into DNA or leads to HAP toxicity. In respect to this hypothesis, it is important that there is a difference in the level of HAP-induced mutagenesis among the strains carrying mutations in the genes of AMP biosynthesis. The less sensitive mutant is ade 3 (Fig. 3 and Table 1). The ADE3 does not directly control any steps of purine biosynthesis. It encodes the $\mathrm{C} 1$ tetrahydrofolate synthase that provides C1-tetrahydrofolate, an indispensable precursor for AMP, histidine, thymidylate, and methionine biosynthesis (see Fig. 4). In this respect it is of interest that ade4, ade16 and ade17 mutants, also defective in IMP biosynthesis, were not found in our screen and were not sensitive to HAP or AHA when constructed de novo and tested directly (data not 
shown). The ADE4 stands apart because PRPP, a substrate of the product of the ADE4 gene, serves as a precursor for additional biosynthetic pathways. This prevents by-product accumulation and might be one of the explanations of lack of HAP sensitivity of the ade4 mutants. The single ade16 and ade17 mutants also do not lead to byproduct accumulation because ADE16 and ADE17 are isozymes and the inactivation of one gene does not block the pathway.

We have found that 6 genes detected in our screening, VIP1, VID27, IPK1, YGR035c, YML013c-a and SHE4, are putatively involved in cell organization or genetically interact with cell-cycle control genes (see Additional file 1 ). This observation provides new perspectives on the mechanisms of base analogs-induced mutagenesis. It is possible that there is a specific structural route, mediated by cell cycle and cytoskeleton components, initiated by penetration of the analog inside the cell to its final target. We have also identified several hypothetical genes critical for the HAP and/or AHA resistance. This may be an initial clue to their functional significance.

Finally, we would like to mention that out of the 18 genes we found to be involved in HAP and AHA sensitivity control, $11(60 \%)$ have orthologs in all groups of organisms, including mammals. Therefore, the results have relevance to higher eukaryotes and humans as well (see Additional file 1).

\section{Conclusion}

We identified novel mutants sensitive to mutagenic and toxic effects of purine base analogs. AHA sensitivity was not previously described for three of the mutants identified in this study. The results reveal a complex control of base analogue mutagenesis by genes encoding the components of metabolic pathways and cytoskeleton.

\section{Methods}

\section{Yeast strains and media}

We have used a set of $4,823 \mathrm{~S}$. cerevisiae mutants carrying deletions of all non-essential ORFs created in the haploid

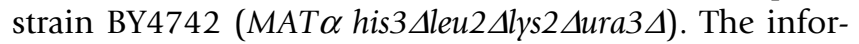
mation about the deletion strains set is available from the Yeast Deletion Project site: ftp://ftp.resgen.com/pub/dele tions/mat alpha 041902.txt. Deletion strains were constructed by replacement of the ORF's with the kanMX4 cassette, which confers resistance to geneticin [36].

The standard yeast complete media (YPD) and minimal synthetic media (SD) were used [37]. Deletion strains were cultivated on YPD medium, supplemented with 200 $\mu \mathrm{g} / \mathrm{ml}$ of geneticin. Sensitivity to HAP and AHA was examined on YPD media containing analogs in concentrations $100 \mu \mathrm{g} / \mathrm{ml}, 10 \mu \mathrm{g} / \mathrm{ml}$ and $1 \mu \mathrm{g} / \mathrm{ml}$. SD medium containing
$40 \mu \mathrm{g} / \mathrm{ml}$ of L-canavanine was used for the selection of Can ${ }^{\mathrm{r}}$ mutants.

\section{Base analogs sensitivity tests}

HAP was purchased from MP Biomedicals (Irvine, California, USA). AHA was custom- synthesized by Dr. I. Kuchuk at the Department of Chemistry of Indiana University (Bloomington, Indiana, USA) by the method of Janion [38]. Both chemicals were dissolved in DMSO (Fisher, USA) with mild heating. A single colony of each tested strain was inoculated into a well of 96-well microtitre plate containing $200 \mu \mathrm{l}$ of liquid YPD medium (see Fig. 2). Microtiter plates were incubated for 2 days at $30^{\circ} \mathrm{C}$ with agitation, to reach a stationary phase (approximately $10^{8}$ cells $/ \mathrm{ml}$ ). For mutagenesis assay, cells were then plated by a multiprong replicator device (approximately 5 $\mu l$ of cell suspension per prong) to the YPD plates containing various concentrations of HAP or AHA, as shown on Fig. 2. After one day of incubation, the plates were replicaplated on SD minimal-medium plates containing L-canavanine. The plates were incubated 5 days and inspected for induction of Can ${ }^{\mathrm{r}}$ mutants.

For the survival test, cell cultures from the microplates were diluted in water in series of 96-well microplates, using a multichanel pipette (see Fig. 2). Diluted cells suspensions were plated to YPD plates containing HAP or AHA by a multiprong replicator device. After 2-3 days of incubation, the number of colonies was recorded. Strains that produced smaller colonies or a smaller number of colonies on the HAP-containing medium, relatively to wild-type strain, were classified as sensitive to killing.

\section{Quantitative assay of the base analog-induced mutagenesis}

For each strain and each concentration of base analogs to be tested, we prepared six independent cultures by inoculating a single colony into $1 \mathrm{ml}$ of liquid YPD medium with or without mutagens. After two days incubation in the roller drum, the mutant frequencies were determined by plating of appropriately diluted cell suspensions on minimal-medium SD plates supplemented with L-canavanine (to determine the number of canavanine-resistant cells per culture), and on YPD plates (to obtain the total number of cells per culture). Then the frequency of mutants was calculated as described [14]. Each experiment was repeated at least three times. We have used several doses of HAP and found that in this type of test the most reproducible results are obtained at dose 25 $\mu \mathrm{g} / \mathrm{ml}$. The statistical significance of differences between variants was estimated by Wilcoxon-Mann-Whitney nonparametric criterion. 


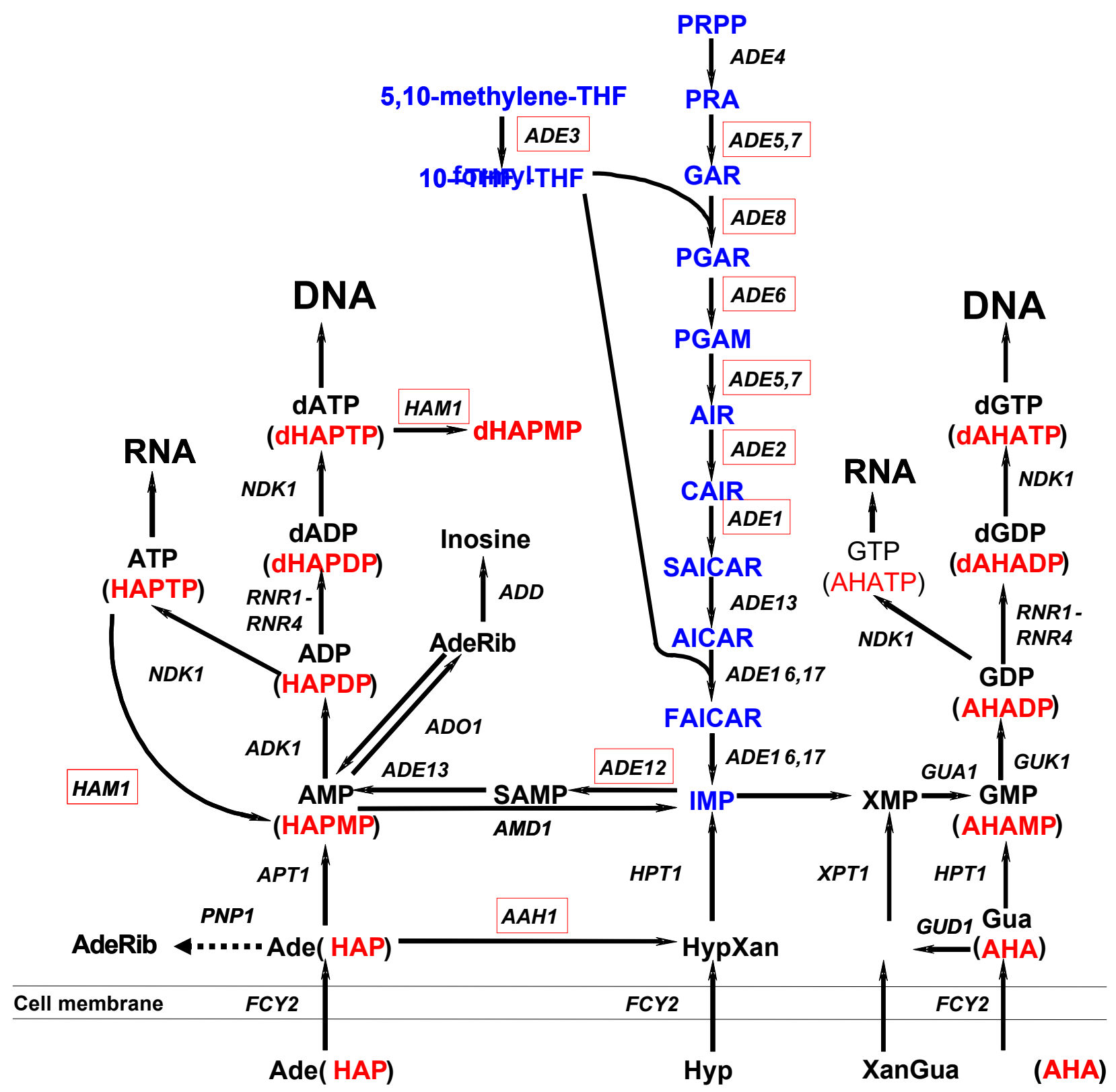

Figure 4

Purine salvage and purine biosynthesis de novo in yeast Saccharomyces cerevisiae. Intermediates of the purine biosynthesis de novo are designated in blue. The salvage pathway is presented in black. Genes, whose deletions lead to HAP and/or AHA sensitivity are highlighted by red boxes. The proposed conversions of HAP and AHA are represented in brackets below the adenine and guanine metabolites, respectively. Dashed arrows represent hypothetical pathways that were not demonstrated experimentally for a given substrate. Abbreviations:Purine biosynthesis de novo: PRPP - 5-phospho-ribosyl-I $\alpha$-pyrophosphate, PRA - 5-phospho- $\beta$-D-ribosylamine, GAR - 5-phosphoribosylglycinamide, FGAR - 5'-phosphoribosyl- $N$-formyl glycinamide, FGAM - 5'-phosphoribosyl-N-formylglycinamidine, AIR - 5'-phosphoribosyl-5-aminoimidazole, CAIR - 5'-phosphoribosyl-5-aminoimidazole-4-carboxylate, SAICAR - 5'-phosphoribosyl-4-(N-succinocarboxamide)-5-aminoimidazole, AICAR - 5'-phosphoribosyl-4-carboxamide-5-aminoimidazole, FAICAR - 5'-phosphoribosyl-4-carboxamide-5-formamidoimidazole, SAMP - adenylosuccinate, 5, I0-methylene-THF - 5, I0-methylenetetrahydrofolate, I0-formyl-THF - I0-formyltetrahydrofolate. Salvage: Ade - adenine, AdeRib - adenosine, Hyp - hypoxanthine, Gua - guanine, Xan - xanthine. 


\section{Authors' contributions}

Youri Pavlov and Elena Stepchenkova designed this study. Elena Stepchenkova performed the experimental work and wrote the initial draft of the manuscript. Vladimir Alenin, Youri Pavlov, Stanislav Kozmin, and Elena Stepchenkova analyzed the data set and wrote the final version of the paper.

\section{Additional material}

\section{Additional File 1}

Annotation of the genes whose deletion results in HAP and AHA

sensitivity

Click here for file

[http://www.biomedcentral.com/content/supplementary/14712156-6-31-S1.pdf]

\section{Acknowledgements}

We are grateful to Polina Shcherbakova for comments during this study and for critical reading of the manuscript. This work was supported in part, by NE DHHS LB506 grant \#9934 for YIP, and by the CRDF grant provided by The Russian Ministry of Education \# ST-012-0.

\section{References}

I. Hochhauser SJ, Weiss B: Escherichia coli mutants deficient in deoxyuridine triphosphatase. J Bacteriol I978, I34(I):|57-I66.

2. Michaels $\mathrm{ML}$, Miller $\mathrm{JH}$ : The $\mathbf{G O}$ system protects organisms from the mutagenic effect of the spontaneous lesion 8hydroxyguanine (7,8-dihydro-8-oxoguanine). J Bacteriol 1992, I 74(20):632I-6325.

3. Grollman AP, Moriya M: Mutagenesis by 8-oxoguanine: an enemy within. Trends Genet 1993, 9(7):246-249.

4. Kamiya $\mathrm{H}$ : Mutagenic potentials of damaged nucleic acids produced by reactive oxygen/nitrogen species: approaches using synthetic oligonucleotides and nucleotides: survey and summary. Nucleic Acids Res 2003, 3 I (2):5 I7-53I.

5. Maki H, Sekiguchi M: MutT protein specifically hydrolyses a potent mutagenic substrate for DNA synthesis. Nature 1992, 355(6357):273-275.

6. Pavlov YI, Noskov VN, Lange EK, Moiseeva EV, Pshenichnov MR Khromov-Borisov NN: The genetic activity of N6-hydroxyadenine and 2-amino-N6-hydroxyadenine in Escherichia coli, Salmonella typhimurium and Saccharomyces cerevisiae. Mutat Res I991, 253(I):33-46.

7. de Serres FJ: The genetic toxicology of 2-amino-N6-hydroxyadenine in eukaryotic organisms: significance for genetic risk assessment. Mutat Res I991, 253(I):5-15.

8. Simandan T, Sun J, Dix TA: Oxidation of DNA bases, deoxyribonucleosides and homopolymers by peroxyl radicals. Biochem J 1998, 335(Pt 2):233-240.

9. Burgis NE, Brucker JJ, Cunningham RP: Repair system for noncanonical purines in Escherichia coli. J Bacteriol 2003, I 85(I0):3|0|-3| I0.

10. Bradshaw JS, Kuzminov A: RdgB acts to avoid chromosome fragmentation in Escherichia coli. Mol Microbiol 2003, 48(6): $171|-| 725$

II. Kouzminova EA, Rotman E, Macomber L, Zhang J, Kuzminov A: RecA-dependent mutants in Escherichia coli reveal strategies to avoid chromosomal fragmentation. Proc Natl Acad Sci U S A 2004, I0I(46): 16262-16267.

12. Noskov V, Negishi K, Ono A, Matsuda A, Ono B, Hayatsu H: Mutagenicity of 5-bromouracil and N6-hydroxyadenine studied by yeast oligonucleotide transformation assay. Mutat Res 1994, 308(I):43-5I.
13. Noskov VN, Staak K, Shcherbakova PV, Kozmin SG, Negishi K, Ono BC, Hayatsu H, Pavlov YI: HAMI, the gene controlling 6-Nhydroxylaminopurine sensitivity and mutagenesis in the yeast Saccharomyces cerevisiae. Yeast 1996, I 2(I): 17-29.

14. Shcherbakova PV, Noskov VN, Pshenichnov MR, Pavlov YI: Base analog 6-N-hydroxylaminopurine mutagenesis in the yeast Saccharomyces cerevisiae is controlled by replicative DNA polymerases. Mutat Res 1996, 369(I-2):33-44.

15. Shcherbakova PV, Pavlov YI: 3'->5' exonucleases of DNA polymerases epsilon and delta correct base analog induced DNA replication errors on opposite DNA strands in Saccharomyces cerevisiae. Genetics 1996, I42(3):717-726.

16. Kozmin SG, Schaaper RM, Shcherbakova PV, Kulikov VN, Noskov VN, Guetsova ML, Alenin VV, Rogozin IB, Makarova KS, Pavlov YI: Multiple antimutagenesis mechanisms affect mutagenic activity and specificity of the base analog 6-N-hydroxylaminopurine in bacteria and yeast. Mutat Res 1998, 402(I-2):4I-50.

17. Kozmin SG, Pavlov YI, Dunn RL, Schaaper RM: Hypersensitivity of Escherichia coli $\Delta$ (uvrB-bio) mutants to 6-hydroxylaminopurine and other base analogs is due to a defect in molybdenum cofactor biosynthesis. J Bacteriol 2000, I 82( I 2):336 I-3367.

18. Pavlov lu I: [Mutants of Saccharomyces cerevisiae supersensitive to the mutagenic effect of 6-N-hydroxylaminopurine]. Genetika 1986, 22(9):2235-2243.

19. Hwang KY, Chung JH, Kim SH, Han YS, Cho Y: Structure-based identification of a novel NTPase from Methanococcus jannaschii. Nat Struct Biol 1999, 6(7):691-696.

20. Chung JH, Park HY, Lee JH, Jang Y: Identification of the dITP- and XTP-hydrolyzing protein from Escherichia coli. J Biochem $\mathrm{Mol}$ Biol 2002, 35(4):403-408.

2I. Lin S, McLennan AG, Ying K, Wang Z, Gu S, Jin H, Wu C, Liu W, Yuan $Y$, Tang $R$, et al.: Cloning, expression, and characterization of a human inosine triphosphate pyrophosphatase encoded by the ITPA gene. J Biol Chem 200I, 276(22): I8695-I870I

22. Giaever G, Chu AM, Ni L, Connelly C, Riles L, Veronneau S, Dow S, Lucau-Danila A, Anderson K, Andre B, et al.: Functional profiling of the Saccharomyces cerevisiae genome. Nature 2002, 4 I 8(6896):387-39I.

23. Bennett CB, Lewis LK, Karthikeyan G, Lobachev KS, Jin YH, Sterling JF, Snipe JR, Resnick MA: Genes required for ionizing radiation resistance in yeast. Nat Genet 200I, 29(4):426-434.

24. Birrell GW, Giaever G, Chu AM, Davis RW, Brown JM: A genomewide screen in Saccharomyces cerevisiae for genes affecting UV radiation sensitivity. Proc Natl Acad Sci U S A 200I, 98(22): |2608-|26|3. Epub |200| Oct I26|6

25. Chang $M$, Bellaoui $M$, Boone $C$, Brown GW: A genome-wide screen for methyl methanesulfonate-sensitive mutants reveals genes required for $\mathbf{S}$ phase progression in the presence of DNA damage. Proc Natl Acad Sci U S A 2002, 99(26): 16934-16939. Epub I2002 Dec 16913.

26. Game JC, Birrell GW, Brown JA, Shibata T, Baccari C, Chu AM, Williamson MS, Brown JM: Use of a genome-wide approach to identify new genes that control resistance of Saccharomyces cerevisiae to ionizing radiation. Radiat Res 2003, I 60(I): I4-24.

27. Davis-Kaplan SR, Ward DM, Shiflett SL, Kaplan J: Genome-wide analysis of iron-dependent growth reveals a novel yeast gene required for vacuolar acidification. J Biol Chem 2004, 279(6):4322-4329.

28. Huang ME, Rio AG, Nicolas A, Kolodner RD: A genomewide screen in Saccharomyces cerevisiae for genes that suppress the accumulation of mutations. Proc Natl Acad Sci U S A 2003 , I 00(20): I I 529-I I 534

29. Begley TJ, Samson LD: Network responses to DNA damaging agents. DNA Repair (Amst) 2004, 3(8-9): I I23-। I 32.

30. Westmoreland TJ, Marks JR, Olson JA Jr, Thompson EM, Resnick MA Bennett CB: Cell cycle progression in $\mathbf{G I}$ and S phases is CCR4 dependent following ionizing radiation or replication stress in Saccharomyces cerevisiae. Eukaryot Cell 2004, 3(2):430-446.

31. Weber E, Rodriguez C, Chevallier MR, Jund R: The purine-cytosine permease gene of Saccharomyces cerevisiae : primary structure and deduced protein sequence of the FCY2 gene product. Mol Microbiol I990, 4(4):585-596.

32. Koz'min SG, Domkin VD, Zekhnov AM, Pavlov lu I: [Genetic control of metabolism of a mutagenic analog of 6-N-hydroxylaminopurine bases in Saccharomyces cerevisiae yeasts]. Genetika 1997, 33(5):591-598. 
33. Hartenstein RC, Fridovich I: Adenine aminohydrolase. An investigation of specificity. J Biol Chem 1967, 242(4):740-746.

34. Sollitti P, Merkler DJ, Estupinan B, Schramm VL: Yeast AMP deaminase. Catalytic activity in Schizosaccharomyces pombe and chromosomal location in Saccharomyces cerevisiae. J Biol Chem 1993, 268(6):4549-4555.

35. Rebora K, Desmoucelles C, Borne F, Pinson B, Daignan-Fornier B: Yeast AMP pathway genes respond to adenine through regulated synthesis of a metabolic intermediate. Mol Cell Biol 200I, 2 I (23):790I-79|2.

36. Wach A, Brachat A, Pohlmann R, Philippsen P: New heterologous modules for classical or PCR-based gene disruptions in Saccharomyces cerevisiae. Yeast 1994, I0(13): 1793-1808.

37. Rose M, Winston F, Hieter P: Methods in Yeast Genetics. A Laboratory Course Manual. Cold Spring Harbor, NY: Cold Spring Harbor Laboratory Press; 1990.

38. Janion C: The synthesis and properties of N6-substituted 2amino-purine derivatives. Acta Biochim Pol 1976, 23(1):57-68.

Publish with Bio Med Central and every scientist can read your work free of charge

"BioMed Central will be the most significant development for disseminating the results of biomedical research in our lifetime. "

Sir Paul Nurse, Cancer Research UK

Your research papers will be:

- available free of charge to the entire biomedical community

- peer reviewed and published immediately upon acceptance

- cited in PubMed and archived on PubMed Central

- yours - you keep the copyright

Submit your manuscript here:

http://www.biomedcentral.com/info/publishing_adv.asp
BiolMedcentral 